\title{
Current status of malaria parasite among blood donors in Port Harcourt, Rivers State, Nigeria
}

\author{
${ }^{* 1} \mathrm{ABAH}, \mathrm{AE} ;{ }^{2} \mathrm{JOE}-\mathrm{Cliff}, \mathrm{O}$ \\ ${ }^{I}$ Department of Animal and Environmental Biology, Faculty of Science, University of Port Harcourt, PMB 5323 \\ Port Harcourt 50001, Rivers State, Nigeria. \\ ${ }^{2}$ School of Science Laboratory Technology, University of Port Harcourt, PMB 5323, Port Harcourt. \\ ${ }^{1}$ Corresponding author.Email: austin.abah@uniport.edu.ng; aeabah@yahoo.com
}

\begin{abstract}
This study was carried out to determine the prevalence of malaria parasite among blood donors at the Police Clinic Port Harcourt, Rivers State, Nigeria. The standard parasitological techniques using both thick and thin blood films from the donors for the detection of malaria parasite was followed. Venous blood was collected from 200 blood donors and films were made on clean greese-free glass slide and stained with $10 \%$ Giemsa stains and viewed under the microscope using the oil immersion objective. Of the 200 samples examined, $56(28.00 \%)$ were positive with Plasmodium falciparium. The highest prevalence among the males $53(26.50 \%)$ and between the ages 21 -30years and only $3(1.50 \%)$ of females were positive. Donors having the blood group O were more infected $(60.70 \%)$ than the other blood groups and the lowest was blood group $\mathrm{AB}(5.40 \%)$. This result shows that there is a relatively high prevalence of malaria parasite among the blood donors in Port Harcourt, Nigeria. It is, therefore, recommended that malaria parasite screening test be included among other blood screening tests before any transfusion to avert the deleterious effects of malaria on recipients. (C) JASEM
\end{abstract}

http://dx.doi.org/10.4314/jasem.v20i1.22

KEYWORDS: Malaria parasite; Prevalence; Blood Donors; Port Harcourt; Rivers State.

\section{Introduction.}

The transmission of malaria parasites by blood transfusion has been one of the first reported incidents of transfusion-transmitted infections (Kitchen and Chiodini, 2006).The administration of Blood is a lifesaving procedure and has greatly increased over the years. Every second, someone in the world needs blood (WHO, 2011). In every country, surgery, trauma, severe anaemia and complications of pregnancy are among clinical conditions that demand blood transfusion (WHO, 2011). Transmission of Malaria by blood transfusion is a significant public health problem especially in the malaria endemic regions of the world (WHO, 1996). Transfusion-transmitted malaria (TTM) was first described in 1911(Kitchen and Chiodini, 2006). Although the international policies recommended that blood for transfusion should be screened for transfusion- transmitted infections, but more often, malaria screening is not performed in most malariaendemic countries in sub-Saharan Africa (OwusuOfori et al., 2010). This is despite the World Health Organizations' recommendation that all donated blood should be tested for malaria where appropriate and possible (WHO, 2009).
Transfusion-transmitted malaria can have serious consequences, as infection with Plasmodium falciparum may prove rapidly fatal (Kitchen and Chiodini, 2006). The presence of Malaria in the blood may lead to fatalities when such blood is transfused especially into children under 5years, pregnant women, serious blood loss in accident victims, and immuno- suppressive patients (WHO, 1996). In developed countries, tests have been developed to detect Plasmodium antiboides and these are used for selected blood donors in various blood centres. They also use tests to detect Plasmodium antigens and nucleic acid amplification testing (NAT) for parasitic DNA (Reesink et al., 2010).Prevalence of transfusion -transmitted malaria varies from $0.6 \%$ to above $50 \%$ in sub-Saharan Africa (Owusu-Ofori et al., 2013). Malaria is highly endemic in Nigeria. In fact, Nigeria has more reported cases of deaths due to malaria than any other country in the world (CDC, 2012). Even at that, as in most of sub-Saharan Africa, blood donors are not routinely screened for malaria infections in most facilities (Falade et al.,2009).

Some studies have been done in Nigeria to ascertain the prevalence of Malaria among blood donors. Falade et al.,(2009) reported $20.2 \%$ by microscopic method. Erhabor et al., (2007) recorded 10.2\%

${ }^{\text {I} C o r r e s p o n d i n g ~ a u t h o r . ~ E m a i l: ~ a u s t i n . a b a h @ u n i p o r t . e d u . n g ; ~ a e a b a h @ y a h o o . c o m ~}$ 
among donors in the Niger Delta of Nigeria while Pondei et al., (2012) reported $12.5 \%$ in screened blood in a tertiary health centre in Niger Delta. Chikwem et al.,(1997) reported $4.1 \%$ in Maiduguri, Northern Nigeria while Akinboye and Ogunrinade (1987) reported $7.8 \%$ at Ibadan, Nigeria. Uneke et al., (2006) reported $40.9 \%$ in south-Eastern Nigeria while Epidi et al., (2008) recorded $51.5 \%$ in Abakaliki. Oladeinde et al., (2014) reported $27.5 \%$ and $13.8 \%$ among commercial and volunteer donors respectively. These studies indicate a wide spread of prevalence of malaria among blood donors in Nigeria. However, there is paucity of information on this issue in Port Harcourt, which is the third most important urban centre in Nigeria due to oil exploration and exploitation and other commercial activities. The present study was conducted to appraise the current level of malaria infection among blood donors in Port Harcourt.

\section{MATERIALS AND METHODS}

Ethical considerations. Permission was sought and obtained from the authorities of the Police Clinic and the Department of Animal and Environmental Biology research committee. Also consent was obtained from the Blood Donors who gave verbal consent.

Sample collection.: Venous blood was collected from 200 randomly selected healthy blood donors (192 males and 8 females) at the Police Clinic Port Harcourt, Rivers State, Nigeria. The donors were within the ages of 18-60 year. Five milliliters of blood was collected from each participant and was gently dispensed into Ethylene Diamine Tetra-Acetic acid (EDTA) bottle and mixed properly. Collected samples were transported to the parasitology laboratory of the Department of Animal and
Environmental Biology of the University of Port Harcourt.

Sample Preparation and Examination. Thick and Thin blood films were prepared, air dried and stained and examined following the method described by Cheesbrough (2005). The thin films were fixed with methanol and all films were stained with $10 \%$ Giemsa stain diluted with 7.2 buffered water for 10minutes following the standard procedure described by Cheesbrough (2005).

Blood grouping was done using antisera: Anti A, Anti B and Anti D on a clean white tile. A drop of the antisera was placed separately on the tile, a drop of blood was added to each and with the help of a glass rod, it was mixed properly and rocked gently. ABO blood groups were determined by agglutination as adopted from Cheesbrough (2005).

\section{RESULTS AND DISCUSSIONS}

Out of the total of 200 blood samples examined in this study, $56(28.00 \%)$ were infected. From the studied population, 192 were males and only 8 were females .A breakdown of the infections on bases of sex is presented in table 1 . The age group recruited for the study was between 18 to 60 years. Highest rate of infection of $50 \%$ was observed among the age group of 20-30 years (Table 2). This was followed by the age group of 31-40 years with infection rate of $32.1 \%$. Plasmodium falciparum was the only Plasmodium species identified in the present study. Blood group $\mathrm{O}$ was the dominant blood group found in the study and most parasitized (60.7\%) while blood group $\mathrm{AB}$ was the least and also the least parasitized (5.4\%).Table 3 showed Plasmodium falciparum infections among various blood groups.

Table 1: Plasmodium faciparium infections according to sex

\begin{tabular}{lllll}
\hline$\underline{\text { Sex }}$ & \multicolumn{1}{c}{ No. Examined } & & No Infected & \% Infected \\
\hline Male & 192 & 53 & $26.50 \%$ \\
Female & 8 & 3 & $1.50 \%$ \\
$\underline{\text { Total }}$ & $\underline{200}$ & $\underline{56}$ & $\underline{28.00 \%}$ \\
\hline
\end{tabular}

Table 2: Plasmodium falciparium infections according to age groups

\begin{tabular}{|c|c|c|c|}
\hline Age range & No.Examined & No. Infected & \% Infected \\
\hline $10-20$ & 15 & 2 & 3.57 \\
\hline $21-30$ & 95 & 28 & 50 \\
\hline $31-40$ & 55 & 18 & 32.14 \\
\hline $41-50$ & 25 & 4 & 7.14 \\
\hline $51-60$ & 10 & 4 & 8.14 \\
\hline Total & $\underline{200}$ & $\underline{56}$ & $\underline{100}$ \\
\hline
\end{tabular}


Table 3: Plasmodium falciparium infections among various blood groups

\begin{tabular}{llll}
\hline Blood group & Total Number & No. Infected & \% infected \\
\hline A & 48 & 12 & 21.4 \\
B & 39 & 7 & 12.5 \\
AB & 7 & 3 & 5.4 \\
O & 106 & 34 & 60.7 \\
Total & $\underline{\mathbf{2 0 0}}$ & $\underline{\mathbf{5 6}}$ & $\underline{\mathbf{1 0 0}}$
\end{tabular}

Present investigation revealed that out of a total of 200 blood donors screened for Plasmodium parasites $56(28.00 \%)$ haboured the parasites. The prevalence of $28.00 \%$ is relatively high and should be a cause for concern as recipients of these bloods are mostly pregnant women, children under 5years, accident victims and other immuno-suppressive patients. More so, it has been established that Transfusiontransmitted malaria can have serious consequences, as infection with Plasmodium falciparum may prove rapidly fatal (Kitchen and Chiodini, 2006). Again this high prevalence calls for concern when compared with report from previous research by Erbahor et al.,(2007) who reported $10.2 \%$ and $12.5 \%$ by Pondei et al.,(2012) in the Niger Delta area as the prevalence in the present study is more than twice the value reported in each of their work. Howbeit, it agrees with Oladeinde et al.,(2014) who reported $27.5 \%$.But lower than Uneke et al's (2006) $40.5 \%$ in south Eastern Nigeria and Epidi et al's.,(2008) 51.5 in Abakiliki. These variations may be as a result of what has been established earlier, that Prevalence of transfusion -transmitted malaria varies from 0.2 cases per million in non-endemic countries to 50 or more cases in per million in endemic areas. Also the prevalence of malaria parasitaemia among blood donors had been reported to be as high as $55 \%$ in the highly endemic northern Nigeria (Owusu-Ofori et al., 2010).

The high prevalence is worrisome because Ninetyfive percent of transfusions in Nigeria and entire subSaharan Africa involve whole blood rather than components (Owusu-Ofori et al., 2010). Wholeblood and red blood cell concentrates are the most common source of transfusion transmitted malaria (Owusu-Ofori et al., 2010). But blood donors are not separated from the prevailing environmental conditions that facilitates the transmission of the malaria parasites in any community, they do not live in isolation. They are exposed to acquisition of malaria like any other persons living in the endemic area. Although healthy adults living in malariaendemic areas have some immunity to developing clinical malaria, the recipients of blood transfusions in sub-Saharan Africa are predominantly children and pregnant women who are likely to be immunologically compromised (Owusu-Ofori et al., 2010) . Thus the high prevalence in this set of asymptomatic cases buttresses the fact that Nigeria is highly endemic for malaria parasite and has more reported cases of deaths due to malaria than any other country in the world (CDC, 2012). This high prevalence lays more credence to the World Health Organizations' recommendation that all donated blood should be tested where appropriate and possible (WHO, 2009), as currently malaria screening is not performed in most facilities Nigeria (Falade, 2009) and most malaria-endemic countries in sub-Saharan Africa (Owusu-Ofori et al., 2010).

Plasmodium falciparum was the only species of malaria parasite identified in the present study. The finding in the present study is similar to that of pondei et al.,(2012) and Abah and Temple (2015).This lays additional emphasis to the WHO's earlier report that Plasmodium falciparum is the most common of the four human malaria parasites across much of Sub-Saharan Africa. (The other three parasites are $P$. vivax, $P$. malariae, and $P$. ovale.) (WHO, 2003).

Out of the $28.0 \%$ infected in the present study, 26 . $5 \%$ were males while $1.5 \%$ was female. This was expected because more males (192) presented themselves for blood donation than females (8) and this corroborates Bani and Giussani's (2010) observations that gender plays key role in the motivation to give blood(women being more altruistic, men being more individualistic) and in adverse reactions. Thus fewer women are regular donors.

Age related prevalence showed that those within the 21-30years were more infected (50\%) than all the other groups. Similar observation was recorded by Uneke et al., (2006). Larger population of donors were in this age- group which may be as a result of adventure or pecuniary gain. However, WHO had observed that younger people in malaria endemic 
areas are more susceptible to malaria infections than the older people (WHO, 2003).

On the blood group, in this study, People in Blood group $\mathrm{O}$ were more than those of the other blood groups. The reason for this difference is not clear but $60.70 \%$ of the percentage infected with malaria parasite in the study were in blood group O. Earlier report by Oladeinde et al., (2014), suggested that people in blood group $\mathrm{O}$ have higher burden of malaria parasite and engage much more frequently in repeated blood donation than persons of other blood groups.

Conclusion: The prevalence of malaria parasite infection among blood donors in Port Harcourt is high from the present study. Therefore, it is recommended that screening for malaria parasitaemia be included in the routine investigation of potential blood donors in Nigeria. This is because breaking the transmission chain from blood donors to recipients is another step at achieving that desired goal of curbing malaria infections and reducing deaths due to malaria to near zero worldwide.

Acknowledgement. We are grateful to the authorities of Police Clinic port Harcourt for the permission to collect samples, the blood donors for obliging us their blood samples, Mrs H.Onoja for her assistance during the laboratory work and O.C.Umeozor for reading through and making his comments.

\section{REFERENCES.}

Abah AE; Temple B (2015), Prevalence of Malaria Parasite among Asymptomatic Primary School Children in Angiama Community,Bayelsa State, Nigeria.

Tropical Medicine and Surgery 4(1):203-207

Akinboye DO; Ogunrinade AF (1987), Malaria and Loaisis among blood donors at Ibadan, Nigeria. Transaction of the Royal Society of Tropical Medicine and Hygiene 81(3):398-399.

Bani Marco; Giussani Barbara (2010): Gender differences in giving blood: a review of the literature. Blood Transfusion, 8(4): 278-287

CDC (Centre for Disease Control) (2012), Atlanta co 800-CDC-info.US Dept. and Health.

Cheesbrough M (2005), District Laboratory Manual for tropical countries. $2^{\mathrm{Nd}}$ Edition updated Vol. 1. Bulterworth -heinemann Ltd. Oxford ox28DP.pp. 249.
Chikwem JO, Mohammed I, Okara GC, Ukwandu NCD, Ola TO (1997), Prevalence of transmissible blood infections among blood donors at the University of Maiduguri Teaching Hospital, Maiduguri, Nigeria.

East African Medical Journal 74(4)::213-216

Epidi TT,Nwani CD, Ugorji NP (2008),prevalence of malaria in blood donors in Abakaliki. Scientific Research and essays, 3(4): 162-164

Erhabor O, Ok O, Awah I, Uko KE ,Charles AT (2007), The prevalence of Plasmodia parasitaemia among donors in the Niger delta of Nigeria.Tropical Doctors. 37(1):32-34

Falade.CO, Nash O, Akingbola, TS, Michael OS, Olojede F, Ademowo (2009), Blood banking in malaria endemic area: evaluating the problem posed by malarial Parasitaemias.

Annals of Tropical Medicine and Parsitology, 103(5) pp 383-392.

Kitchen AD, Chiodini PL (2006), Malaria and blood transfusion. Vox Sanguinis International Journal of Transfusion Medicine, 90:77-84.

Oladeinde BH, Omoregie R, Osakue EO, Onaiwu TO (2014), Asymptomatic malaria

among Blood Donors in Benin city Nigeria. Iran Journal of Parasitology 9(3): 415-422

Owusu-Ofori AK, Parry C, Bates I

(2010), Transfusion-transmitted malaria in countries where malaria is endemic: a review of the literature from sub-Saharan Africa.

Clinical Infectious Diseases, 51:1192-1198

Owusu-Ofori Alex K,Martha Betson,Christopher M.Parry, J.Russell Stothard,Imelda Bates (2013), Transfusion-Transmitted Malaria in Ghana clinical Infectious Diseases

56(12):1735-1740

Pondei kemebradikumo, Ebidor Lawani, Eno Ndiok (2012), Prevalence of the malaria parasite in screened blood in a tertiary health centre in the malaria-endemic

Niger Delta region of Nigeria. Global Advance Research Journal of Microbiology, 1(11):188-193.

${ }^{*} \mathrm{ABAH}, \mathrm{AE} ;{ }^{2} \mathrm{JOE}$-Cliff, $O$ 
Reesink HW, Panzer S, Wendel S, Levi JE, Ullum H, Ekblom-Kullberg S, Seifried E, SchmidtM, Shinar E, Prati D, Berzuini A, Ghosh S, Flesland O, Jeansson S, Zhiburt E, Piron M, Sauleda S, Ekermo B, Eglin R, Kitchen A, Dodd RY, Leiby DA, Katz LM, Kleinman S (2010), The use of malaria antibody tests in the prevention of transfusion- transmitted malaria. Vox Sanguinis International Journal of Transfusion Medicine 98:468-478.

Uneke CJ, Ogbu O, Nwojiji V (2006), Potential risk of induced Malaria by blood transfusion in South-eastern Nigeria. Mcgill journal of Medicine, 9(1):8-13

WHO (World Health Organization) (1996), Blood Transfusion Safety, Geneva.
WHO (World Health Organization) (2003), African malaria report. Geneva:

WHO press

http//www.who.int/malaria/publication/atoz/who cdsmal 20031093/en/.2003

Assessed $23^{\text {rd }}$ Oct 2015.

WHO (World Health Organization) (2009), Blood Transfusion Safety; testing of donated blood

http://www.who.int/bloodsafety/testing_processi ng/en/.2009. Assessed $12^{\text {th }}$ Sept 2015.

WHO (World Health Organization) ( 2011), Department of Essential Health Technologies: Blood Transfusion Safety. Geneva 